\title{
The Ser290Asn and Thr715Pro Polymorphisms of the SELP Gene Are Associated with A Lower Risk of Developing Acute Coronary Syndrome and Low Soluble P-Selectin Levels in A Mexican Population ${ }^{\dagger}$
}

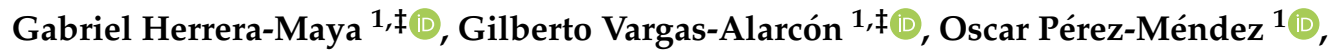 \\ Rosalinda Posadas-Sánchez ${ }^{2}{ }^{(0)}$, Felipe Masso ${ }^{3}$, Teresa Juárez-Cedillo ${ }^{4}\left(\mathbb{D}\right.$, Galileo Escobedo ${ }^{5}$, \\ Andros Vázquez-Montero ${ }^{1}$ and José Manuel Fragoso ${ }^{1, * \mathbb{D}}$ \\ 1 Department of Molecular Biology, Instituto Nacional de Cardiología Ignacio Chávez, Mexico City 14080, \\ Mexico; mayadermata@ciencias.unam.mx (G.H.-M.); gvargas63@yahoo.com (G.V.-A.); \\ opmendez@yahoo.com (O.P.M.); koapa_93and@hotmail.com (A.V.-M.) \\ 2 Department of Endocrinology, Instituto Nacional de Cardiología Ignacio Chávez, Mexico City 14080, Mexico; \\ rossy_posadas_s@yahoo.it \\ 3 Laboratory of Translational Medicine, UNAM-INC Research Unit, Instituto Nacional de Cardiología, \\ Ignacio Chávez, Mexico City 14080, Mexico; f_masso@yahoo.com \\ 4 Commissioned of the Research Unit in Clinical Epidemiology, Hospital Regional No. 1, Dr. Carlos McGregor \\ Sánchez Navarro, Instituto Mexicano del Seguro Social, Mexico City 14080, Mexico; \\ terezillo@exalumno.unam.mx \\ 5 Unit of the Experimental Medicine, Hospital General de Mexico, Dr. Eduardo Liceaga, Mexico City 14080, \\ Mexico; gescobedog@msn.com \\ * Correspondence: mfragoso1275@yahoo.com.mx; Tel.: (52-55)-5573-2911 (ext. 26302); Fax: (52-55)-5573-0926 \\ + Running Head: SELP gene polymorphisms in acute coronary syndrome. \\ $\ddagger \quad$ The contributions by G. Herrera-Maya and G. Vargas-Alarcón are equal and the order of authorship \\ is arbitrary.
}

Received: 14 January 2020; Accepted: 10 February 2020; Published: 11 February 2020 updates

\begin{abstract}
Recent studies have shown that P-selectin promotes the early formation of atherosclerotic plaque. The aim of the present study was to evaluate whether the SELP gene single nucleotide polymorphisms (SNPs) are associated with presence of acute coronary syndrome (ACS) and with plasma P-selectin levels in a case-control association study. The sample size was estimated for a statistical power of $80 \%$. We genotyped three SELP (SELP Ser290Asn, SELP Leu599Val, and SELP Thr715Pro) SNPs using 5' exonuclease TaqMan assays in 625 patients with ACS and 700 healthy controls. The associations were evaluated with logistic regressions under the co-dominant, dominant, recessive, over-dominant and additive inheritance models. The genotype contribution to the plasma P-selectin levels was evaluated by a Student's t-test. Under different models, the SELP Ser290Asn $\left(\mathrm{OR}=0.59, p C_{C o \text {-Dominant }}=0.047 ; \mathrm{OR}=0.59, p C_{\text {Dominant }}=0.014 ; \mathrm{OR}=0.58, p C_{\text {Over-Dominant }}=0.061\right.$, and $\left.\mathrm{OR}=0.62, p C_{\text {Additive }}=0.015\right)$ and SELP Thr715Pro $\left(\mathrm{OR}=0.61, p C_{\text {Dominant }}=0.028 ; \mathrm{OR}=0.63\right.$, $p C_{\text {Over-Dominant }}=0.044$, and $\left.\mathrm{OR}=0.62, p C_{\text {Additive }}=0.023\right)$ SNPs were associated with a lower risk of ACS. In addition, these SNPs were associated with low plasma P-selectin levels. In summary, this study established that the SELP Ser290Asn and SELP Thr715Pro SNPs are associated with a lower risk of developing ACS and with decreased P-selectin levels in plasma in a Mexican population.
\end{abstract}

Keywords: acute coronary syndrome; P-selectin; genetics; polymorphisms; susceptibility 


\section{Introduction}

Acute coronary syndrome (ACS) comprises a spectrum of obstructive coronary artery diseases that most commonly arise from plaque rupture and/or erosion, leaving the vulnerable lipid-rich core exposed to the circulation. As a result, platelets and the coagulation cascade are activated, leading to acute thrombotic occlusion [1,2]. This syndrome is a consequence of atherosclerosis associated with a strong inflammatory component, which is immune mediated by chemokines. These molecules have an important role in the development of atherosclerotic plaque [3-5]. P-selectin is a chemokine, which mediates lymphocyte and monocyte recruitment, rolling, and diapedesis to the areas of inflammation [4-6]. Experimental studies have shown that higher expression of SELP increases adhesion, monocytes rolling to the vascular wall, accumulation of oxidized low-density lipoproteins, and the early formation of atherosclerotic plaque and other inflammatory diseases [4-7].

P-selectin contains 17 exons and is encoded by the SELP gene located on chromosome 1q21-q24 spanning $<50 \mathrm{~kb}$ [8]. Recently, three single nucleotide polymorphism (SNPs) in the SELP gene in the exons 7, 12, and 13 [positions G1057A Ser290Asn (rs6131), G1980T Leu599Val (rs6133), and A2331C Thr715Pro (rs6136)] have been associated with myocardial infarction, hypertension, coronary heart disease, lupus erythematosus, type 2 diabetes mellitus (T2DM), and atherosclerosis [8-13]. Nonetheless, the association between these SNPs and other inflammatory diseases, such as diabetic retinopathy and multiple sclerosis is controversial, with negative results [14,15].

Considering the prominent role of P-selectin as a key in the chain of events leading to atherosclerotic plaque formation, the aim of this study was to investigate the association of three SELP SNPs (Ser290Asn, Leu599Val and Thr715Pro) with the risk of developing ACS. Furthermore, we evaluated whether these SNPs were associated with plasma P-selectin levels in a Mexican population sample.

\section{Subjects and Methods}

\subsection{Study Population}

This case-control study was carried out at the Instituto Nacional de Cardiologia Ignacio Chavez. The sample size was calculated for unmatched cases and controls with OpenEpi software (http: //www.openepi.com/SampleSize/SSCC.html) with a statistical power of $80 \%$ and an alpha error of 0.05 . Using this criterion, we included 625 patients with ACS ( $82 \%$ men and $18 \%$ women with a mean age of $57.97 \pm 10.5$ years) who were diagnosed based on clinical characteristics, electrocardiographic changes and biochemical markers of cardiac necrosis, according to guidelines from the European Society of Cardiology (ESC) and American College of Cardiology (ACC) [16,17]. The exclusion criteria were (1) patients with clear inflammatory pathologies on admission, such as infection established by clinical, laboratory, or image investigations, and (2) patients with an autoimmune disease or cancer previously diagnosed or documented during their hospitalization. Moreover, we included 700 healthy controls ( $66 \%$ men and $34 \%$ women with a mean age of $54.37 \pm 7.65$ years) coming from the Genetics of Atherosclerosis Disease (GEA) Mexican study previously described by Rosalinda-Posadas et al [18]. All healthy controls were asymptomatic and apparently healthy individuals without a family history of CAD and with a negative calcium score, indicative of the absence of subclinical atherosclerosis [18]. The exclusion criteria included not only the use anti-dyslipidemic, anti-hypertensive, and anti-diabetic drugs at the time of the study, but also congestive heart failure, as well as liver, renal, thyroid or oncological disease. All GEA participants were unrelated and of self-reported Mexican ancestry (3 generations). A Mexican mestizo was defined as a person who (1) was born in Mexico and (2) is a descendant of the original autochthonous inhabitants and of individuals (Caucasian and/or African, mainly Spaniards) who migrated to America in or after the XVI century. This study was conducted according to the principles of the Declaration of Helsinki and was approved by the Ethics and Research committee of our institution (registration number: 17CI09012010). Written informed consent was obtained from all individuals enrolled in the study. 


\subsection{Laboratory Analyses}

After a 12-h overnight fast, EDTA blood samples were drawn and centrifuged within $15 \mathrm{~min}$ after collection; the plasma was separated into aliquots and immediately analyzed or frozen at $-80{ }^{\circ} \mathrm{C}$ until analysis. Cholesterol and triglyceride plasma concentrations were determined by enzymatic/colorimetric assays (Randox Laboratories, UK). The phosphotungstic acid- $\mathrm{Mg}^{2+}$ method was used to determine HDL-C concentrations. LDL-C was estimated in samples with a triglyceride level lower than $400 \mathrm{mg} / \mathrm{dl}$, using the modified Friedewald formula [19]. Plasma lipid concentrations were determined within $24 \mathrm{~h}$ after blood sample collection. We followed the National Cholesterol Education Project (NCEP) Adult Treatment Panel (ATP III) guidelines and thus defined dyslipidemia with the following levels: cholesterol $>200 \mathrm{mg} / \mathrm{dl}$, LDL-C $>130 \mathrm{mg} / \mathrm{dl}, \mathrm{HDL}-\mathrm{C}<40 \mathrm{mg} / \mathrm{dl}$, and triglyceride > $150 \mathrm{mg} / \mathrm{dl}$ (http://www.nhlbi.nih.gov/guidelines/cholesterol/atp3_rpt.htm). Type 2 diabetes mellitus (T2DM) was defined with a fasting glucose $\geq 126 \mathrm{mg} / \mathrm{dL}$ and was also considered when participants reported glucose-lowering treatment or a physician diagnosis of T2DM. Hypertension was defined by a systolic blood pressure $\geq 140 \mathrm{mmHg}$ and/or diastolic blood pressure $\geq 90 \mathrm{mmHg}$, or the use of oral antihypertensive therapy [18].

\subsection{Genetic Analysis}

DNA extraction was performed from peripheral blood in agreement with the method of Lahiri and Nurnberger [20]. The SELP G1057A Ser290Asn, SELP G1980T Leu599Val, and SELP A2331C Thr715Pro SNPs were genotyped using 5' exonuclease TaqMan assays on a 7900HT Fast Real-Time PCR system according to manufacturer's instructions (Applied Biosystems, foster City, CA, USA). In order to avoid genotyping errors, ten percent of the samples were determined twice; the results were concordant for all cases.

\subsection{Determination of P-Selectin Levels}

Samples were aliquoted and stored at $-70{ }^{\circ} \mathrm{C}$ for further use. Plasma P-selectin levels were measured using a quantitative sandwich enzyme immunoassay technique (ELISA) kit in accordance with the manufacturer's instructions (Human P-Selectin/CD62P Quantikine ELISA Kit, R\&D systems). The detection range was $0.8-50.00 \mathrm{ng} / \mathrm{mL}$ and the sensitivity was equal to the minimal detectable dose of this kit $(\geq 0.121 \mathrm{ng} / \mathrm{mL})$.

\subsection{Functional Prediction Analysis}

Two in silico programs, the ESEfinder (http://rulai.cshl.edu/cgi-bin/tools/ESE3/esefinder.cgi? process=home) and SNP Function Prediction (http://snpinfo.niehs.nih.gov/cgi-bin/snpinfo/snpfunc.cgi) were used to predict the possible functional effect of the SELP SNPs. Both programs (ESEfinder2.0 and SNPinfo) analyzed the localization of the SNPs (e.g., 5'-upstream, 3'-untranslated regions, intronic) and their possible functional effects, such as amino acid changes in protein structure, transcription factor binding sites in promoter or intronic enhancer regions, and alternative splicing regulation by disrupting exonic splicing enhancers (ESE) or silencers [21,22].

\subsection{Statistical Analysis}

All statistical analysis in this study was performed using SPSS version 18.0 (SPSS, Chicago, Il). Data of continuous variables were expressed as median and percentiles (25th-75th), while data of discrete variables [e.g., frequency (n, \%)] were analyzed using Chi-squared or Fisher's exact tests. We used logistic regression tests to associate the SNPs with ACS under five inheritance models [16]. The correction of the p-values $(\mathrm{pC})$ was performed with the Bonferroni test. Using the HAPLOVIEW version 4.1 software (Cambridge, MA, USA), we performed the haplotypes construction and linkage disequilibrium analysis $\left(\mathrm{LD}, \mathrm{D}^{\prime \prime}\right)$. We tested whether our study population was in Hardy-Weinberg equilibrium (HWE) with a Chi-square test. Furthermore, we used the QUANTO 
software [http://biostats.usc.edu/software] to calculate the statistical power of our study and found it was 0.80 . Using the Student's t-test, we analyzed the contribution of the genotypes on the P-selectin plasma levels. The values were expressed as means \pm SD. The level of significance was set at $\mathrm{p}<0.05$.

\section{Results}

\subsection{Characteristics of the Study Population}

Clinical and biochemical characteristics of the ACS patients and healthy controls are shown in Table 1. There were significant differences between the ACS patients and healthy controls. Compared to healthy controls, the ACS patients had a higher frequency of T2DM, hypertension, dyslipidemia, and smoking habit. Conversely, the total cholesterol, triglycerides, and LDL-C levels in ACS patients were lower than those in the control group; this effect may be due to their treatment with statins.

Table 1. Clinical characteristics and biochemical parameters of the study individuals.

\begin{tabular}{ccccc}
\hline & & $\begin{array}{c}\text { ACS } \\
(n=625)\end{array}$ & $\begin{array}{c}\text { Healthy Controls } \\
(\boldsymbol{n}=\mathbf{7 0 0})\end{array}$ & $p$-Value \\
\hline & & $\begin{array}{c}\text { Median (percentile } \\
25-75)\end{array}$ & $\begin{array}{c}\text { Median (percentile } \\
25-75)\end{array}$ & \\
\hline Age (years) & $57.72(51-65)$ & $54.39(49-59)$ & $<0.001$ \\
\hline BMI $\left(\mathrm{kg} / \mathrm{m}^{2}\right)$ & $27.3(25-29)$ & $28.3(26-31)$ & 0.001 \\
\hline Blood pressure $(\mathrm{mmHg})$ & Systolic & $130.61(114-144)$ & $117.32(106-126)$ & $<0.001$ \\
\cline { 2 - 5 } & Diastolic & $80.1(70-90)$ & $72.47(66-77)$ & $<0.001$ \\
\hline Glucose $(\mathrm{mg} / \mathrm{dl})$ & & $158.51(102-188)$ & $98.73(84-99)$ & $<0.001$ \\
\hline Total cholesterol $(\mathrm{mg} / \mathrm{dl})$ & & $164.22(128-198)$ & $190.4(164-210)$ & $<0.001$ \\
\hline HDL-C $(\mathrm{mg} / \mathrm{dl})$ & & $38.32(32-44)$ & $44.6(35-53)$ & $<0.001$ \\
\hline LDL-C $(\mathrm{mg} / \mathrm{dl})$ & & $106.4(76-133)$ & $115.8(94-134)$ & $<0.001$ \\
\hline Triglycerides $(\mathrm{mg} / \mathrm{dl})$ & & $169.2(109-201)$ & $175.1(112-208)$ & 0.218 \\
\hline Gender $\mathrm{n}(\%)$ & Male & $510(82)$ & $463(66)$ & $<0.001$ \\
\hline Smoking $\mathrm{n}(\%)$ & Female & $115(18)$ & $237(34)$ & \\
\hline Hypertension & Yes & $225(35)$ & $155(22)$ & $<0.001$ \\
\hline Diabetes mellitus & Yes & $355(57)$ & $206(29)$ & $<0.001$ \\
\hline Dyslipidemia $\mathrm{n}(\%)$ & Yes & $218(35)$ & $68(10)$ & $<0.001$ \\
\hline
\end{tabular}

Data are expressed as median and percentiles (25th-75th). $p$-values were estimated using Mann-Whitney U test for continuous variables and chi-square test for categorical values. ACS: acute coronary syndrome patients.

\subsection{Allele and Genotype Frequencies}

Genotype frequencies of the SNPs were in HWE. The frequencies of the SELP Leu599Val SNP was similar in ACS patients and healthy controls. Nonetheless, the SNPs [SELP Ser290Asn, and SELP Thr715Pro] were associated with a lower risk of ACS (Table 2). Under co-dominant, dominant, over-dominant, and additive models, the $A$ (290Asn) allele of the SELP Ser290Asn SNP was associated with a lower risk of $\mathrm{ACS}\left(\mathrm{OR}=0.59, p C_{C o \text {-Dom }}=0.047 ; \mathrm{OR}=0.59, p C_{\mathrm{Dom}}=0.014 ; \mathrm{OR}=0.58\right.$, $p C_{\text {Over } \text {-Dom }}=0.061$, and $\mathrm{OR}=0.62, p C_{\text {Add }}=0.015$, respectively). In the same way, under dominant, over-dominant, and additive models, the $C$ (715Pro) allele of the SELP Thr715Pro SNP was associated with a lower risk of $\mathrm{ACS}\left(\mathrm{OR}=0.61, p C_{\text {Dom }}=0.028 ; \mathrm{OR}=0.63, p C_{\text {Over-Dom }}=0.044\right.$, and $\mathrm{OR}=0.62$, $p C_{\text {Add }}=0.023$, respectively). All models were adjusted for gender, age, blood pressure, BMI, glucose, total cholesterol, HDL-C, LDL-C, triglycerides, and smoking habit. 
Table 2. Distribution of SEL-P polymorphisms in ACS patients and healthy controls.

\begin{tabular}{|c|c|c|c|c|c|c|c|}
\hline & & & & MAF & Model & OR $(95 \% \mathrm{CI})$ & $p C$ \\
\hline \multicolumn{8}{|c|}{ SELP G1057A Ser290Asn (rs6131) } \\
\hline & GG & GA & $\mathrm{AA}$ & & & & \\
\hline $\begin{array}{l}\text { Control } \\
(n=691)\end{array}$ & $569(0.823)$ & $115(0.166)$ & $7(0.010)$ & 0.09 & $\begin{array}{l}\text { Co-dominant } \\
\text { Dominant } \\
\text { Recessive }\end{array}$ & $\begin{array}{l}0.59(0.38-0.92) \\
0.59(0.39-0.90) \\
0.58(0.12-2.83)\end{array}$ & $\begin{array}{c}0.047 \\
0.014 \\
0.49\end{array}$ \\
\hline $\operatorname{ACS}(n=617)$ & $541(0.877)$ & $73(0.118)$ & $3(0.005)$ & 0.06 & $\begin{array}{l}\text { Over-dominant } \\
\text { Additive }\end{array}$ & $\begin{array}{l}0.61(0.39-0.92) \\
0.62(0.42-0.92)\end{array}$ & $\begin{array}{l}0.019 \\
0.015\end{array}$ \\
\hline \multicolumn{8}{|c|}{ SELP G1980T Leu599Val (rs6133) } \\
\hline & GG & GT & TT & & & & \\
\hline $\begin{array}{l}\text { Control } \\
(n=682)\end{array}$ & $563(0.825)$ & $114(0.167)$ & $5(0.007)$ & 0.09 & $\begin{array}{l}\text { Co-dominant } \\
\text { Dominant } \\
\text { Recessive }\end{array}$ & $\begin{array}{l}0.28(0.02-3.32) \\
1.07(0.73-1.58) \\
0.27(0.02-3.26)\end{array}$ & $\begin{array}{l}0.46 \\
0.73 \\
0.26\end{array}$ \\
\hline $\operatorname{ACS}(n=611)$ & $505(0.827)$ & $105(0.172)$ & $1(0.002)$ & 0.09 & $\begin{array}{l}\text { Over-dominant } \\
\text { Additive }\end{array}$ & $\begin{array}{l}1.12(0.75-1.66) \\
1.02(0.71-1.49)\end{array}$ & $\begin{array}{l}0.57 \\
0.90\end{array}$ \\
\hline \multicolumn{8}{|c|}{ SELP A2331C Thr715Pro (rs6136) } \\
\hline & AA & $\mathrm{AC}$ & $\mathrm{CC}$ & & & & \\
\hline $\begin{array}{l}\text { Control } \\
(n=685)\end{array}$ & $580(0.847)$ & $97(0.141)$ & $8(0.012)$ & 0.08 & $\begin{array}{l}\text { Co-dominant } \\
\text { Dominant } \\
\text { Recessive }\end{array}$ & $\begin{array}{l}0.63(0.40-0.99) \\
0.61(0.39-0.95) \\
0.36(0.04-2.95)\end{array}$ & $\begin{array}{c}0.075 \\
0.028 \\
0.32\end{array}$ \\
\hline $\operatorname{ACS}(n=607)$ & $537(0.884)$ & $67(0.110)$ & $3(0.005)$ & 0.06 & $\begin{array}{l}\text { Over-dominant } \\
\text { Additive }\end{array}$ & $\begin{array}{l}0.63(0.40-0.99) \\
0.62(0.41-0.94)\end{array}$ & $\begin{array}{l}0.044 \\
0.023\end{array}$ \\
\hline
\end{tabular}

ACS, acute coronary syndrome, MAF, minor allele frequency, OR, odds ratio, $\mathrm{CI}$, confidence interval, $p C, p$-value corrected. The $\mathrm{p}$-values were calculated by the logistic regression analysis, and the ORs were adjusted for gender, age, blood pressure, BMI, glucose, total cholesterol, HDL-C, LDL-C, triglycerides, and smoking habit.

Considering that the prevalence of T2DM (35\%) and hypertension $(57 \%)$ are highest in ACS patients versus healthy controls ( $10 \%$ and $29 \%$, respectively), we performed a sub-analysis of the polymorphisms associated with a low risk of ACS (SELP Ser290Asn and SELP Thr715Pro). This analysis was made comparing individuals with and without T2DM and the other hand, individuals with and without hypertension. The results show that both polymorphisms were not associated with T2DM or with hypertension (Supplementary Tables S1 and S2). Therefore, this analysis corroborates that the genetic variation of these polymorphisms of the SELP gene are associated to the ACS, and not comes of the T2DM or hypertension.

\subsection{Linkage Disequilibrium Analysis}

We used the Haploview version 4.1 program for the analysis of the linkage disequilibrium and construction of haplotypes. In this analysis, the SELP Thr715Pro and SELP Leu599Val SNPs showed a strong linkage disequilibrium $\left(\mathrm{D}^{\prime}=0.95\right)$. In addition, Haploview revealed strong evidence of recombination of the polymorphisms SELP Thr715Pro versus SELP Ser290Asn and SELP Leu599Val versus SELP Ser290Asn ( $\mathrm{D}^{\prime}=0.17$ and $\mathrm{D}^{\prime}=0.28$, respectively; data not shown). This analysis marked three haplotypes with different distributions in ACS patients and healthy controls (Table 3). The "Thr-Leu-Ser" haplotype was associated with a higher risk of developing ACS (OR $=1.28,95 \%$ CI: 1.05-1.54, pC = 0.006), while the "Pro-Leu-Ser" and "Thr-Leu-Asn" haplotypes were associated with a lower risk of developing ACS (OR $=0.72,95 \% \mathrm{CI}$ : $0.52-0.99, \mathrm{pC}=0.022$, and $\mathrm{OR}=0.71,95 \% \mathrm{CI}$ : $0.51-1.00, \mathrm{pC}=0.027$, respectively). 
Table 3. Haplotype frequencies (Hf) of SEL-P haplotypes in ACS patients and healthy controls.

\begin{tabular}{ccccccccc}
\hline Haplotypes & Thr715Pro & Leu599Val & Ser290Asn & $\begin{array}{c}\text { ACS } \\
(\mathbf{n}=\mathbf{6 0 5})\end{array}$ & $\begin{array}{c}\text { Controls } \\
(\mathbf{n}=\mathbf{6 7 6})\end{array}$ & OR & 95\%CI & P \\
\hline H1 & Thr & Leu & Ser & 0.804 & 0.763 & 1.28 & $1.05-1.54$ & 0.006 \\
\hline H2 & Thr & Val & Ser & 0.073 & 0.067 & 1.08 & $0.80-1.47$ & 0.32 \\
\hline H3 & Pro & Leu & Ser & 0.057 & 0.077 & 0.72 & $0.52-0.99$ & 0.022 \\
\hline H4 & Thr & Leu & Asn & 0.049 & 0.066 & 0.71 & $0.51-1.00$ & 0.027 \\
\hline H5 & Pro & Val & Asn & 0.014 & 0.022 & 0.62 & $0.33-1.13$ & 0.063 \\
\hline
\end{tabular}

Abbreviations: Hf, Haplotype frequency; $P, p$-value; OR, odds ratio; $95 \% \mathrm{CI}$, confidential interval. The order of the polymorphisms in the haplotypes is according to the positions in the chromosome (SELP A2331C Thr715Pro (rs6136), SELP G1980T Leu599Val (rs6133), and SELP G1057A Ser290Asn (rs6131). Bold numbers indicate significant associations.

\subsection{Association of Polymorphisms with Plasma P-Selectin Levels}

In order to define the functional effect of the SELP Ser290Asn and SELP Thr715Pro SNPs associated with a lower risk of ACS, we determined the plasma levels of P-selectin in individuals with different genotypes of these two polymorphisms. For this analysis, we included a subgroup of 30 healthy controls for SELP Ser290Asn (7 AA, $11 \mathrm{GA}$ and $12 \mathrm{GG}$ ) and a subgroup of 30 healthy controls for the SELP Thr715Pro SNP $(8 C C, 11 A C$ and $11 A A)$. In this study, we did not include the analysis of plasma P-selectin levels in patients with ACS, due to the fact that in the setting of the coronary syndrome, the comorbidities, such as insulin resistance/T2DM, hypertension, and inflammatory processes, as well as the use of the anti-dyslipidemic and/or anti-hypertensive drugs, may have altered the inflammatory markers levels, such as inflammatory cytokines, adhesion molecules, and C-reactive protein, masking the real impact of SELP polymorphisms on plasma P-selectin levels [23-25]. In this context, subjects carrying the $A A$ (Ans/Ans) genotype of the SELP Ser290Asn SNP had a lower P-selectin plasma concentration $(33.93 \pm 9.79 \mathrm{ng} / \mathrm{mL})$ than carriers of the $G G$ (Ser/Ser) $(44.76 \pm 6.54 \mathrm{ng} / \mathrm{mL}, p=0.032)$ or GA (Ser/Ans) genotypes (48.04 $\pm 16.57 \mathrm{ng} / \mathrm{mL}, p=0.049)$ (Figure 1A). On the other hand, the analysis of the SELP Thr715Pro polymorphism showed that individuals with the CC (Pro/Pro) genotype had a lower concentration of P-selectin $(26.44 \pm 10.77 \mathrm{ng} / \mathrm{mL})$ than $A A$ (Thr/Thr) carriers ( $55.35 \pm 14.05 \mathrm{ng} / \mathrm{dl}$, $p=0.001$ ). In addition, the individuals with the $A C$ (Thr/Pro) genotype had lower P-selectin levels than $A A$ (Thr/Thr) carriers $(34.91 \pm 14.46 \mathrm{ng} / \mathrm{dl}, p=0.005)$ (Figure 1B).

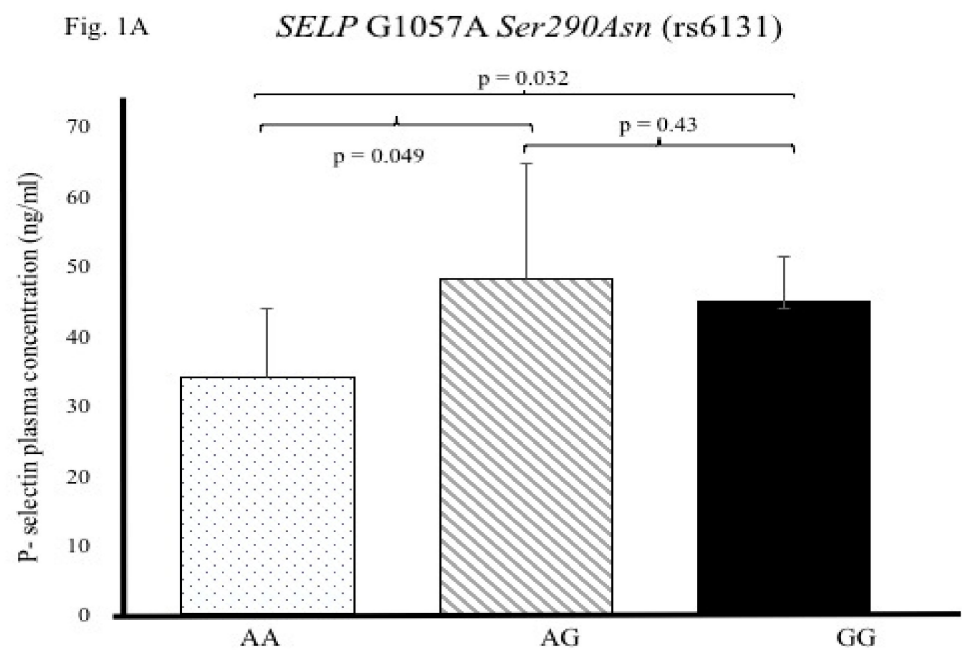

Figure 1. Cont. 
Fig.1B SELP A2331C Thr715Pro (rs6136)

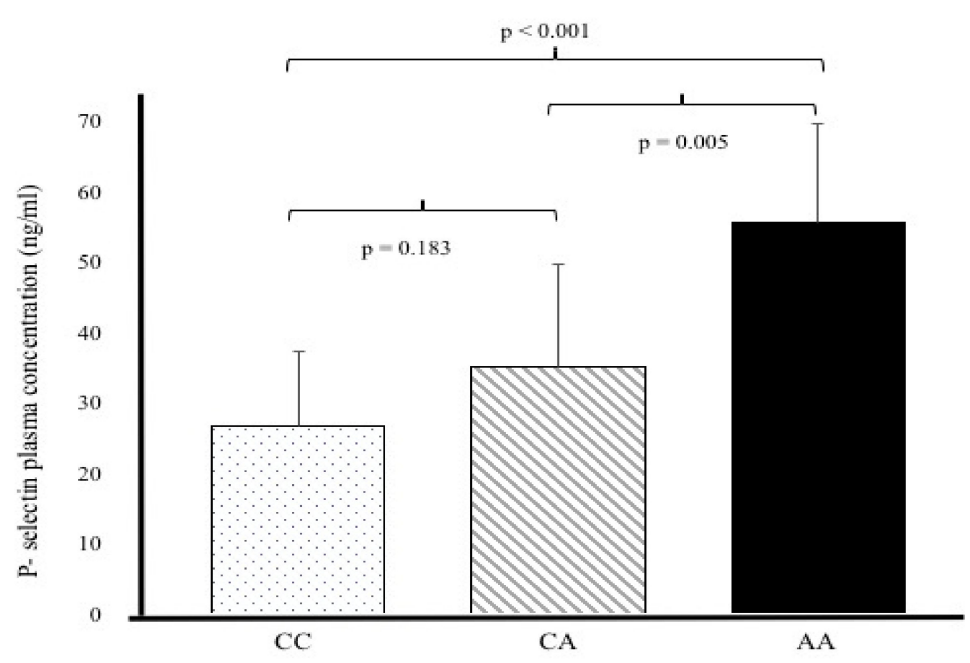

Figure 1. Genetic contribution of the SELP G1057A and SELP A2331C polymorphisms on P-selectin levels. (A) P-selectin plasma levels in individuals with different genotypes of the SELP G1057A polymorphism. (B) P-selectin plasma levels in individuals with different genotypes of the SELP A2331C polymorphism.

\subsection{Functional Prediction}

The functional prediction analysis showed that the presence of the $A$ (Asn) allele of the SELP Ser290Asn polymorphism potentially produces a binding motif for Srp40 protein. In contrast, no evidence of potentially functional motifs was found for the SELP Thr715Pro polymorphism.

\section{Discussion}

In this study, we analyzed three relevant polymorphisms (Ser290Asn, Leu599Val, and Thr715Pro, respectively) of the SELP gene. The association of these SNPs with several inflammatory diseases in different populations is controversial, with positive and negative results [8-15]. In our study, the distribution of the SELP Leu599Val SNP was similar in both ACS patients and healthy controls. Nonetheless, the presence of the 290Asn and 715Pro alleles (SELP Ser290Asn and SELP Thr715Pro polymorphisms, respectively) was associated with a lower risk of developing ACS. In the same way, Reiner et al. reported in the CARDIA study that the SELP Ser290Asn and SELP Thr715Pro SNPs are associated with carotid intima-media thickness in young adults; however, these associations are different in European-American and African-American individuals [9]. In line with these data, Nasibullin et al. reported that the 290Ans allele of the SELP Ser290Asn SNP is associated with a lower risk of MI in a Russian population [13]. Similarly, the study of the risk of atherosclerosis in communities (ARIC), as well as the study of the Framingham heart (FHS) have shown that the genotype Pro715Pro is associated with a decreased risk of atherosclerosis in American and European populations $[26,27]$. In contrast with these data, in the ARIC study, Volcik et al. reported that the 290Ans and 715Pro alleles (SELP Ser290Asn and SELP Thr715Pro SNPs, respectively) were associated with the development of coronary heart disease in white but not in African Americans [11]. Similarly, Timasheva et al. reported that the 290Ans allele of the SELP Ser290Asn SNP is associated with the development of hypertension in ethnic Tatars originating from the Republic of Bashkortostan (Russian Federation) [12]. By the same token, Kou et al. reported that Thr715Pro or Pro715Pro genotypes of the SELP Thr715Pro polymorphism increased the risk of developing cardiovascular diseases (CVD) in a Chinese Han population [28]. Additionally, we found that the H3 (Pro-Leu-Ser) and H4 (Thr-Leu-Asn) haplotypes were associated with a lower risk of developing ACS, whereas H1 (Thr-Leu-Ser) was associated with a higher risk. As can be seen, the haplotypic combinations between SELP Thr715Pro 
and SELP Ser290Asn polymorphisms were not in linkage disequilibrium. Nonetheless, the protection haplotypes carry 715Pro and 290Ans alleles, and both of them were associated independently with a lower risk of cardiovascular diseases and other inflammatory diseases. This finding corroborated the role of these two alleles with the presence of ACS, whether they were analyzed independently or as haplotypes.

It is important to note that ACS patients and the healthy donors have much greater variation in blood glucose (102-188 versus 84-99) and diabetes mellitus (35\% versus 10\%). Considering these data, it is important to establish whether the polymorphisms are associated with T2DM or hypertension. In a sub-analysis, we showed that both polymorphisms were not associated with T2DM or with hypertension.

As can be seen, the associations of the SELP Ser290Asn and SELP Thr715Pro polymorphisms with ACS are contradictory in different study populations. We suggest that these discrepancies could be due to the classical cardiovascular risk factors and the environmental factors, such as diet, exercise, and lifestyle, which have an important role in the development of inflammatory diseases [29,30]. Another reason may be the fact that the allelic distribution of these polymorphisms varies according to the ethnic origin of the study populations. According to data obtained from the National Center for Biotechnology Information, populations from European, Asian, and African ancestry in Southwest US present a higher frequency of the $A$ allele of the SELP G1057A Ser290Asn (rs6131) polymorphism $(21.7 \%, 20.2 \%$ and $32.9 \%$, respectively) when compared to Mexican mestizos and white American populations with a lower frequency of the $A$ allele ( $9 \%$ and $14 \%$, respectively). Concerning the SELP A2331C Thr715Pro (rs6136) SNP, Mexican mestizos, Europeans, and white Americans present a higher frequency of the $C$ allele $(8 \%, 8.8 \%$, and $8.2 \%$, respectively) than populations with Asian and African ancestry (0.2\% and 2.5\%, respectively) (https://www.ncbi.nlm.nih.gov/variation/tools/1000genomes/), (https://www.ensembl.org/index.html).

We further determined the effect of the SELP gene polymorphisms on plasma P-selectin levels using genotype groups. We found that the AA (290 Asn/Asn) and CC (715 Pro/Pro) genotypes were associated with low P-selectin levels. As far as we know, this is the first study that showed the association of the SELP Ser290Asn and SELP Thr715Pro polymorphisms in P-selectin levels in individuals without the use of the anti-dyslipidemic or anti-hypertensive drugs. These drugs may modify the levels of the inflammatory markers, such as pro-inflammatory cytokines, adhesion molecules and C-reactive protein, masking the real impact of SELP gene polymorphisms on plasma P-selectin [23-25]. Nonetheless, the results concerning the association between P-selectin plasma levels and heart diseases are still contradictory. For example, Reiner et al. reported in the CARDIA study that the $A$ (290Asn) and C (715Pro) alleles are associated with decreased plasma P-selectin levels and with the risk of developing atherosclerosis [9]. By the same token, Volcik et al. documented that the 715Pro allele is associated with lower P-selectin levels in the Atherosclerosis Risk in Communities (ARIC) study [27]. Similarly, Lee et al. determined that the lower serum levels of P-selectin decreased the risk of atherosclerosis [26]. At the same time, other reports have shown that the 715Pro $(C)$ allele increased the expression of SELP mRNA, as well as the concentration of P-selectin levels in other inflammatory diseases, such as rheumatoid arthritis and T2DM [8,31]. As far as we know, the precise mechanism by which low and/or high P-selectin levels are associated with ACS remains to be elucidated. Nonetheless, recent data provide evidence that P-selectin upregulation on the endothelial cell surface mediates the effects of angiotensin II (Ang II), which has an important role in the development atherosclerosis [32]. In addition, Ang II stimulates not only the production of several molecules (adhesion molecules, chemokines, and cytokines) but also the oxidation and uptake of LDL, which promotes endothelial dysfunction [6,32]. On the other hand, Ang II triggers the synthesis of matrix metalloproteinases, the plasminogen activator inhibitor-1, and the proliferation of vascular smooth cells; this effect leads to the destabilization of atherosclerotic plaques [6]. Furthermore, using bioinformatics tools, we determined the potential effect of the SELP gene polymorphisms associated with ACS. The analysis of the SELP Thr715Pro polymorphism did not provide evidence of potential functional motifs. Nonetheless, the analysis of 
the SELP Ser290Asn polymorphism showed that the 290 Asn $(A)$ allele generates a binding site for the Srp40 proteins. These proteins have multiple functions in the pre-mRNA splicing process, as well as in the regulation of alternative splicing, which leads to the production of protein isoforms $[33,34]$. In this context, we think that future investigations are warranted to understand the effect of these polymorphisms on P-selectin levels.

Some limitations should be considered. The P-selectin levels were only measured in a small sample of control individuals and experiments on RNA transcription or protein stability were not made. Considering these limitations, the effect of the SNPs on P-selectin plasma levels should be taken with care and studies in a large number of individuals are necessary to corroborate this association. In the same way, in our study it was not possible to determine the expression levels of P-selectin on the leukocyte's surface to confirm the data obtained in plasma.

In summary, this study demonstrated that the SELP Ser290Asn and SELP Thr715Pro polymorphisms are associated with a lower risk of developing ACS in a Mexican population. It was possible to distinguish two haplotypes (Pro-Leu-Ser and Thr-Leu-Asn) associated with a lower risk of developing ACS. On the other hand, both polymorphisms were associated with lower P-selectin levels in plasma. Lastly, due to the specific genetic characteristics of the Mexican population, we consider that additional studies will need to be undertaken in a larger number of individuals and in populations with different ethnic origins; these studies could help define the true role of these polymorphisms as markers of risk or protection from developing ACS and other cardiovascular events.

Supplementary Materials: The following are available online at http://www.mdpi.com/2218-273X/10/2/270/s1, Table S1. Distribution of Ser290Asn and Thr715Pro SEL-P polymorphisms in individuals with and without T2DM. Table S2. Distribution of Ser290Asn and Thr715Pro SEL-P polymorphisms in individuals with and without hypertension.

Author Contributions: Conceptualization, G.H.-M., G.V.-A., O.P.-M. and J.M.F.; Data curation, O.P.-M., T.J.-C. and A.V.-M.; Formal analysis, G.H.-M., R.P.-S., F.M., T.J.-C., G.E., A.V.-M. and J.M.F.; Investigation, G.V.-A., O.P.-M. and J.M.F.; Methodology, O.P.-M., R.P.-S., F.M., G.E. and A.V.-M.; Resources, G.H.-M., O.P.-M., T.J.-C. and G.E.; Software, G.H.-M., R.P.-S., F.M., T.J.-C., G.E. and A.V.-M.; Supervision, J.M.F.; Validation, A.V.-M.; Writing original draft, J.M.F.; Writing - review \& editing, G.V.-A. and J.M.F. All authors have read and agreed to the published version of the manuscript.

Funding: This research was funded by the Consejo Nacional de Ciencia y Tecnología (CONACyT), Mexico City, Mexico (Project number 233277).

Acknowledgments: This work was submitted in fulfilment of the requirements to obtaining the Doctoral degree of Gabriel Herrera-Maya in the PhD program of Biological Sciences of the Universidad Nacional Autónoma de Mexico (UNAM). Gabriel Herrera-Maya was supported by a fellowship from the Consejo Nacional de Ciencia $y$ Tecnología (CONACyT) Mexico City, Mexico with CVU number 545322. The authors are grateful to the study participants. Institutional Review Board approval was obtained for all sample collections. The authors would like to thank the technicians Silvestre Ramirez-Fuentes and Marva Arellano-Gonzalez for their participation in sample collection and DNA extraction.

Conflicts of Interest: The authors declare no conflict of interest.

\section{Abbreviations}

$\begin{array}{ll}\text { HDL-C } & \text { High-density lipoprotein-cholesterol } \\ \text { LDL } & \text { Low-density lipoprotein-cholesterol } \\ \text { SELP } & \text { P-selectin gene } \\ \text { T2DM } & \text { Type 2 diabetes mellitus } \\ \text { SNP } & \text { Single nucleotide polymorphism } \\ \text { ACS } & \text { Acute coronary syndrome }\end{array}$

\section{References}

1. Libby, P. Inflammation and Atherosclerosis. Nature 2002, 420, 868-874. [CrossRef]

2. Virmani, R.; Kolodgie, F.D.; Burke, A.P.; Finn, A.V.; Gold, H.K.; Tulenko, T.N.; Wrenn, S.P.; Narula, J. Atherosclerotic plaque progression and vulnerability to rupture: angiogenesis as a source of intraplaque hemorrhage. Arterioscler. Thromb. Vasc. Biol. 2005, 25, 2054-2061. [CrossRef] [PubMed] 
3. Achar, S.A.; Kundu, S.; Norcross, W.A. Diagnosis of acute coronary syndrome. Am. Fam. Physician. 2005, 72, 119-126. [PubMed]

4. Braunersreuther, V.; Mach, F.; Steffens, S. The specific role of chemokines in atherosclerosis. Thromb. Haemost 2007, 97, 714-721. [CrossRef]

5. Aukrust, P.; Halvorsen, B.; Yndestad, A.; Ueland, T.; Oie, E.; Otterdal, K.; Gullestad, L.; Damås, J.K. Chemokines and cardiovascular risk. Arterioscler. Thromb. Vasc. Biol. 2008, 28, 1909-1919. [CrossRef]

6. Montezano, A.C.; Nguyen Dinh Cat, A.; Rios, F.J.; Touyz, R.M. Angiotensin II and Vascular Injury. Curr. Hypertens Rep. 2014, 16, 431. [CrossRef]

7. Bland, A.D.; Nadar, S.K.; Lip, G.Y.H. The adhesion molecule P-selectin and cardiovascular disease. Eur. Heart J. 2003, 24, 2166-2179. [CrossRef]

8. Kaur, R.; Singh, J.; Kapoor, R.; Kaur, M. Association of SELP polymorphisms with soluble P-selectin levels and vascular risk in patients with type 2 diabetes mellitus: a case-control study. Biochem. Genet. 2019, 57, 73-97. [CrossRef]

9. Reiner, A.P.; Carlson, C.S.; Thyagarajan, B.; Reider, M.J.; Polak, J.F.; Siscovick, D.S.; Nickerson, D.A.; Jacobs, D.R., Jr.; Gross, M.D. Soluble P-selectin, SELP polymorphisms, and atherosclerotic risk European-American and African-African young adults: the coronary artery risk development in young adults (CARDIA) study. Arterioscler. Thromb. Vasc. Biol. 2008, 28, 1549-1555. [CrossRef]

10. Morris, D.L.; Graham, R.R.; Erwig, L.P.; Gaffney, P.M.; Moser, K.L.; Behrens, T.W.; Vyse, T.J.; Graham, D.C. Variation in the upstream region of P-selectin (SELP) is a risk factor for SLE. Genes Immun. 2009, 10, 404-413. [CrossRef] [PubMed]

11. Volcik, K.A.; Ballantyne, C.M.; Coresh, J.; Folsom, A.R.; Boerwinkle, E. Specific P-selectin and P-selectin glycoprotein ligand-1 genotypes/haplotypes are associated with risk of incidence CHD and ischemic stroke: the atherosclerosis risk in communities (ARIC) study. Atherosclerosis 2007, 195, e76-e82. [CrossRef] [PubMed]

12. Timasheva, Y.R.; Nasibullin, T.R.; Imaeva, E.B.; Erdman, V.; Kruzliak, P.; Tuktarova, I.A.; Nikolaeva, I.E.; Mustafina, O.E. Polymorphisms of inflammatory markers and risk of essential hypertension in Tartars from Russia. Clin. Exp. Hypertens. 2015, 37, 398-403. [CrossRef] [PubMed]

13. Nasibullin, T.R.; Timasheva, Y.R.; Sadikova, R.I.; Tuktarova, I.A.; Erdman, V.V.; Nikolaeva, I.E.; Sabo, J.; Kruzliak, P.; Mustafina, O.E. Genotype/allelic combinations as potential predictors of myocardial infarction. Mol. Bio. Rep. 2016, 43, 11-16. [CrossRef] [PubMed]

14. Kolahdouz, P.; Yazd, E.F.; Tajamolian, M.; Manaviat, M.R.; Sheikhha, M.H. The rs3917779 polymorphism of P-selectin significant association with proliferative diabetic retinopathy in Yazd, Iran. Graefes Arch. Clin. Exp. Ophthalmol. 2015, 253, 1967-1972. [CrossRef] [PubMed]

15. Fenoglio, C.; Scalabrini, D.; Piccio, L.; de Ris, M.; Venturelli, E.; Cortini, F.; Villa, C.; Serpente, M.; Parks, B.; Rinker, J.; et al. Candidate gene analysis of selectin cluster in patients with multiple sclerosis. J. Neurol. 2009, 256, 832-833. [CrossRef] [PubMed]

16. Cannon, C.P.; Battler, A.; Brindis, R.G.; Cox, J.L.; Ellis, S.G.; Every, N.R.; Flaherty, J.T.; Harrington, R.A.; Krumholz, H.M.; Simoons, M.L.; et al. American College of Cardiology key data elements and definitions for measuring the clinical management and outcomes of patients with acute coronary syndromes. A report of the American College of Cardiology Task Force on Clinical Data Standards (Acute Coronary Syndromes Writing Committee). J. Am. Coll. Cardiol. 2001, 38, 2114-2130.

17. Hamm, C.W.; Bassand, J.P.; Agewall, S.; Bax, J.; Boersma, E.; Bueno, H.; Caso, P.; Dudek, D.; Gielen, S.; Huber, K. ESC Guidelines for the management of acute coronary syndromes in patients presenting without persistent ST-segment elevation: The Task Force for the management of acute coronary syndromes (ACS) in patients presenting without persistent ST-segment elevation of the European Society of Cardiology (ESC). Eur. Heart J. 2011, 32, 2999-3054.

18. Posadas-Sanchez, R.; Perez-Hernandez, N.; Angeles-Martinez, J.; Lopez-Bautista, F.; Villarreal-Molina, T.; Rodríguez-Perez, J.M.; Fragoso, J.M.; Posadas-Romero, C.; Vargas-Alarcón, G. Interleukin 35 Polymorphisms Are Associated with Decreased Risk of Premature Coronary Artery Disease, Metabolic Parameters, and IL-35 Levels: The Genetics of Atherosclerotic Disease (GEA) Study. Mediators Inflamm. 2017, 2017, 6012795. [CrossRef]

19. DeLong, D.M.; DeLong, E.R.; Wood, P.D.; Lippel, K.; Rifkind, B.M. A comparison of methods for the estimation of plasma low- and very low-density lipoprotein cholesterol. The Lipid Research Clinics Prevalence Study. JAMA. 1986, 256, 2372-2377. [CrossRef] 
20. Lahiri, D.K.; Nurnberger, J.I., Jr. A rapid non-enzymatic method for the preparation HMW DNA from blood for RFLP studies. Nucleic Acids Res. 1991, 19, 5444. [CrossRef]

21. Smith, P.J.; Zhang, C.; Wang, J.; Chew, S.L.; Zhang, M.Q.; Krainer, A.R. An increased specificity score matrix for the prediction of SF2/ASF-specific exonic splicing enhancers. Hum. Mol. Genet. 2006, 15, 2490-2508. [CrossRef] [PubMed]

22. Xu, Z.; Taylor, J.A. SNPinfo: integrating GWAS and candidate gene information into functional SNP selection for genetic association studies. Nucleic Acids Res. 2009, 37, W600-W605. [CrossRef] [PubMed]

23. Agabiti Rosei, E.; Morelli, P.; Rizzoni, D. Effects of nifedipine GITS $20 \mathrm{mg}$ or enalapril $20 \mathrm{mg}$ on blood pressure and inflammatory markers in patients with mild-moderate hypertension. Blood Press Suppl. 2005, 1, 14-22. [CrossRef] [PubMed]

24. Golia, E.; Limongelli, G.; Natale, F.; Fimiani, F.; Maddaloni, V.; Pariggiano, I.; Bianchi, R.; Crisci, M.; Giordano, R.; Di Palma, G.; et al. Inflamation and cardiuovascular disease: From pathogenesis and therapeutic target. Curr. Atheroscler. Rep. 2014, 16, 435. [CrossRef]

25. Ruszkowski, P.; Masajtis-Zagajewska, A.; Nowicki, M. Effects of combined statin and ACE inhibitor therapy on endothelial function and blood pressure in essential hypertension-a radomised double-blind, placebo controlled crossover study. J. Renin. Angiotensin Aldosterone Syst. 2019, 20, 1-9. [CrossRef]

26. Lee, D.S.; Larson, M.G.; Lunetta, K.L.; Dupuis, J.; Rong, J.; Keaney, J.F., Jr.; Lipinska, I.; Baldwin, C.T.; Vasan, R.S.; Benjamin, E.J. Clinical and genetic correlates of soluble P-selectin in the community. J. Thromb. Haemost. 2008, 6, 20-31. [CrossRef]

27. Volcik, K.A.; Catellier, D.; Folson, A.R.; Matijevic, N.; Wasserman, B.; Boerwinkle, E. SELP and SELPG genetic variation is associated with cell surface measures of SELp and SELPG: the atherosclerosis risk in communities (ARIC) study. Clin. Chem. 2009, 55, 1076-1082. [CrossRef]

28. Kuo, L.; Yang, N.; Dong, B.; Li, Y.; Tang, J.; Qin, Q. Interaction between SELP genetic polymorphisms with inflammatory cytokine interleukin-6 (IL_6) gene variants on cardiovascular disease in Chinese Han population. Mamm. Genome 2017, 28, 436-442.

29. Bielinski, S.J.; Berardi, C.; Decker, P.A.; Kirsch, P.S.; Larson, N.B.; Pankow, J.S.; Sale, M.; De Andrade, M.; Sicotte, H.; Tang, W.; et al. P-selectin and subclinical and clinical atherosclerosis: the multi-ethnic study of atherosclerosis (MESA). Atherosclerosis 2015, 240, 3-9. [CrossRef]

30. Nettleton, J.A.; Matijevic, N.; Follis, J.L.; Folsom, A.R.; Boerwinkle, E. Associations between dietary patterns and flow cytometry-measured biomarkers of inflammation and cellular activation in the Atherosclerosis Risk in Communities (ARIC) Carotid Artery MRI Study. Atherosclerosis 2010, 212, 260-267. [CrossRef]

31. Burkhardt, J.; Blume, M.; Petit-Teixeira, E.; Hugo Teixeira, V.; Steiner, A.; Quente, E.; Wolfram, G.; Scholz, M.; Pierlot, C.; Migliorini, P.; et al. Cellular Adhesion Gene SELP Is Associated with Rheumatoid Arthritis and Displays Differential Allelic Expression. PLoS ONE 2014, 9, e103872. [CrossRef] [PubMed]

32. Piqueras, L.; Kubes, P.; Alvarez, A.; O'Connor, E.; Issekutz, A.C.; Esplugues, J.V.; Sanz, M.J. Angiotensin II Induces leukocyte-endothelial cell interactions in vivo via AT1 and AT2 receptor-mediated P-selectin upregulation. Circulation 2000, 102, 2118-2123. [CrossRef] [PubMed]

33. Tardos, J.G.; Eisenreich, A.; Deikus, G.; Bechhofer, D.H.; Chandradas, S.; Zafar, U.; Rauch, U.; Bogdanov, V.Y. SR proteins ASF/SF2 and SRp55 participoate in tissue factor biosynthesis in human monocyte cells. J. Thromb. Haemost. 2008, 6, 877-884. [CrossRef] [PubMed]

34. Graveley, B.R. Sorting out the complexity of SR protein functions. RNA 2000, 6, 1197-1211. [CrossRef] [PubMed]

(C) 2020 by the authors. Licensee MDPI, Basel, Switzerland. This article is an open access article distributed under the terms and conditions of the Creative Commons Attribution (CC BY) license (http://creativecommons.org/licenses/by/4.0/). 